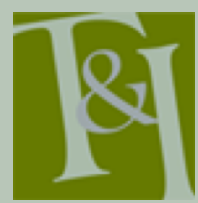

The International Journal for Translation \& Interpreting Research trans-int.org

\title{
Using video technology to engage deaf sign language users in survey research: An example from the Insign project
}

\author{
Jemina Napier \\ Heriot-Watt University \\ J.Napier@hw.ac.uk \\ Katherine Lloyd \\ Heriot-Watt University \\ katjlloyd@gmail.com

\section{Robert Skinner \\ Heriot-Watt University ras3@hw.ac.uk}

\section{Graham H. Turner \\ Heriot-Watt University \\ g.h.turner@hw.ac.uk}

\author{
Mark Wheatley \\ European Union of the Deaf \\ mark.wheatley@eud.eu
}

\begin{abstract}
For many deaf signers, a signed language is their first or preferred language; spoken or written languages are often second languages and literacy levels among deaf signers vary. Historically, surveys carried out with deaf signers have been in written form, which means that findings of such studies may be problematic in terms of whether participants are a representative sample (as only those with higher levels of literacy may respond) and in terms of the integrity of the responses (if respondents did not fully understand questions). This paper therefore discusses issues faced in conducting survey research with deaf signers, given that they may face challenges in accessing questionnaires in written form. The paper also discusses how to conduct a multi-country study with deaf signers when they do not have a common sign language by designing a questionnaire using International Sign. We present a case study of the Insign project, which employed an online survey methodology that allowed 84 deaf respondents from 22 different countries to view questions in International Sign about their experiences with existing communication technologies and their expectations of service provision to access European Institutions. We explore the advantages and disadvantages of such an approach in relation to the use of International Sign, challenges in recruiting enough respondents, the time needed to create a signed questionnaire instrument, and how to enable deaf participants to respond in sign language. We conclude with recommendations for social science researchers to consider when administering surveys with deaf signing communities.
\end{abstract}

Keywords: Deaf, sign language, video technology, online survey research, International Sign

\section{Introduction}

Current research in the social sciences has a tendency to overlook the experiences of deaf signers, and this omission has resulted in the under- 
representation of deaf signers in academic literature (Kusters, De Meulder, \& O'Brien, 2017; Young \& Temple, 2014). The marginalisation of deaf participants within academic research (Singleton, Martin, \& Morgan, 2015) may be attributed to the difficulty faced by researchers who lack sign language skills or funding for sign language interpreters, and some perceive that there has been systematic exclusion of deaf signers in research conducted by hearing researchers who cannot sign (O'Brien \& Emery, 2013). It could also be argued that other minority language users are marginalised from involvement in research as well (O'Brien, 2017; O'Brien \& Emery, 2013). However, even researchers who are fluent in a signed language may face considerable challenges when attempting to utilise traditional social science methods to undertake research with signing communities. Researchers working with deaf signers must "borrow, adapt and sometimes ignore mainstream epistemologies and methodological theory and practice" (Young \& Temple, 2014, p. 5).

Online quantitative surveys are an important example of a methodological tool that historically has proved inadequate for researchers working with deaf signers. Surveys are highly effective within the social sciences for generating large data sets and thus identifying significant trends. There are plenty of examples of multilingual surveys, but it has been identified that there are challenges in translating/adapting or creating such surveys, including issues to do with comprehensibility, quality control, validity, and how to achieve meaning-based equivalence (Forsyth, Kudela, Levin, Lawrence, \& Willis, 2007; Harkness et al., 2010; Sha \& Pan, 2013). The usefulness of the survey method -- which relies on communication via written languages -- has historically been limited for Deaf Studies research as deaf signers may not have adequate literacy levels to access written questionnaires (Freel et al., 2011). Researchers within the field of Deaf Studies are still exploring the most effective means of surveying large numbers of deaf signers using sign language (Young \& Temple, 2014).

While we are aware that many deaf signers who consider themselves to be bilingual in a signed and spoken and/or written language may be content to participate in written surveys, and more are able to effectively participate in surveys that adopt a mixed approach of signed and written languages (Lucas, Mirus, Palmer, Roessler, \& Frost, 2013), we suggest that the use of written language within surveys still presents issues in trying to engage a broader range of deaf signers - who use different national sign languages - as research participants. Alternative approaches are therefore required in order to enhance the participation of deaf signers in academic research, and thereby to ensure that 'institutional audism' (Turner, 2007) is not perpetuated as a result of the insights of this population - as would happen in similar contexts with spoken/written minority languages - being systematically excluded from research outcomes.

In this paper, we explore the affordances offered by digital technologies to improve communication with deaf signers in multilingual research contexts and thus facilitate the inclusion of a much broader range of participants than found in existing quantitative studies. These opportunities are demonstrated in relation to the Insign project (2013-2014), a proof-of-concept study funded through the Director General Justice of the European Commission to test the sustainability of a web-based platform that would enable deaf citizens to communicate directly with European institutions and their representatives using signed and spoken languages (Napier, Skinner, \& Turner, 2017; Turner, Napier, Skinner, \& Wheatley, 2016). The project sought the views of deaf signers from across the European Union on their experiences of existing communication technologies and their expectations of service provision through the use of an online survey. While we are aware of current research using online surveys in the US, where participants typically share a single 
national sign language, the Insign project was unique as it targeted international participants from linguistically diverse signing backgrounds, and thus was cross-cultural. As such, the methodology employed an innovative use of embedded video in International Sign, simple icons, and written questions/answers within an online survey as a means of enhancing participation and clarity of communication between researchers and deaf signers. We examine the advantages and limitations of this approach for enhancing existing research with signers in both Deaf Studies and the wider academic field.

\section{Deaf communities and sign languages}

Before examining the key issues in designing research for deaf signers, it is first necessary to clarify our use of this term. Far from being a singular concept, the category of 'Deaf' is highly complex and political; there are many ways to 'be deaf' (Monaghan, Schmaling, Nakamura, \& Turner, 2003), with increasing recognition that deaf signers have different identities related to their use of sign language, their membership in deaf signing communities, and their interactions with the wider hearing majority (Bat-Chava, 2000; Breivik, 2005; Leigh, 2009; Napier \& Leeson, 2016). Deafness may refer to a physiological condition that affects hearing; in this case, there has been a convention in the literature to use the lower-case 'deaf' to refer to an individual who has a hearing loss but may not necessarily be a signer. In contrast, the use of the uppercase 'Deaf' signifies the cultural identity of belonging to a sign language community (Ladd, 2003). In recent times, however, there has been a move away from this convention due to the complexity of identifying who is 'Deaf' or 'deaf' (Napier \& Leeson, 2016; Turner, 1994), as people may self-identify in different ways and in fact at times be both (Walker, 2016). Instead, the focus is shifting to sign language use, rather than audiological condition, so authors are increasingly referring to 'sign language peoples/persons' or 'signing communities' (Batterbury, Ladd, \& Gulliver, 2007; Jokinen, 2001; Kusters, 2010; Napier \& Leeson, 2016). As evident, from our writing thus far, we adopt the term 'deaf signers' (Kusters et al., 2017).

Various studies have demonstrated the considerable sociolinguistic diversity amongst deaf signers (Lucas, 2001; Schembri \& Johnston, 2013; Schembri \& Lucas, 2015). This variety stems from opportunities to acquire a language (earlier versus later learners), the individual's abilities to acquire and articulate a spoken or signed language, and encompasses a range from those who have been described as displaying 'minimal language skills' (Gregg et al., 2002) to fluent multilinguals (in many cases multilingual across modalities such as speech, reading, writing, and signing). While some deaf signers are able to communicate via spoken and written languages of their country or region, this often remains a 'foreign' or second or third language as it is often acquired later than the signed language (Cannon \& Guardino, 2013). Deaf signers have repeatedly expressed that they feel they are better understood when able to express themselves in their own sign language rather than in written form (Pilling, Fleming, Pechey, Barrett, \& Floyd, 2006; Russell \& Demko, 2013; Taylor, 2009).

There is no such thing as a universal sign language. While in spoken languages, American English and British English are almost interchangeable, American Sign Language (ASL) and British Sign Language (BSL) are almost incomprehensible to native users of each. Similarly, there is no such thing as a 'European' sign language; language variations within the European signlanguage community are just as complex as those found within spoken languages in the EU. In addition to multiple national signed languages, there are also significant regional differences in sign language within national 
contexts. In the UK, for example, there are many dialectical differences in BSL use in Scotland, Northern Ireland, Wales, the North of England, the Midlands, and the South of England (Stamp et al., 2014), where for instance there are 17 different signs for the colour purple ${ }^{1}$.

In addition to these regional and national signing communities, deaf signers are part of a wider transnational community, facilitated by the sociolinguistic permeability of International Sign (IS), which transcends national boundaries (Kusters \& Friedner, 2015; Turner \& Napier, 2014). International Sign is a complex multilingual phenomenon that is frequently classified as a contact language (Adam, 2012); a form of 'foreigner talk' that borrows from various native sign languages, accompanied by other sign language grammatical features (Hansen, 2016; Whynot, 2017).

International Sign is widely used in international settings where those communicating do not share a common signed language, often serving as a more stable lingua franca in large gatherings of deaf people such as conferences, deaf organisation meetings or sporting events (Rosenstock \& Napier, 2016). Deaf signers utilise highly iconic signs, alongside their national language to communicate with an international audience (Rosenstock, 2008). As such, IS has a limited lexicon, drawing heavily on signs from other languages (Whynot, 2017). While it is sometimes classified as a pidgin, researchers within Deaf Studies have argued that the systematic and complex grammatical structures of IS differentiate it from spoken pidgins (Allsop, Woll, \& Brauti, 1995; Hiddinga \& Crasborn, 2011; Supalla, 1991; Suppalla \& Webb, 1995). For these reasons, it is difficult to quantify how many deaf signers use IS worldwide, as it is not a fixed 'language', and some people would state that they do not use IS per se, but instead 'cross-signing', where deaf signers who do not have a shared language use their linguistic and communicative resources to make meaning (Zeshan, 2015).

Some provisos notwithstanding (see section 7 below), the use of IS gives sign language researchers a significant advantage over researchers working with written and spoken languages in multilingual contexts, where English becomes the de facto 'global language' for research. The use of appropriate IS has the potential to avoid prioritising the language preferences of one national community over others and thereby potentially excluding users of minority sign languages.

Not all signers have an audiological condition that affects their hearing and not all deaf people are sign language users. The present authors are largely hearing researchers, with the majority belonging to deaf signing communities, and signers, and we are sensitive to the complexity surrounding the choice of terminology used in relation to research in this area. However, in the context of this paper, issues of self-identification and language preferences amongst signing communities are secondary to the question of whether participants can take part in research that is communicated using written and oral languages. As such, we focus specifically on deaf signers who require or prefer information to be provided in a signed language so that they can clearly understand and pertinently respond to the questions being asked by researchers.

\section{The Insign Project: Leading to evidence-based policy}

The World Federation of the Deaf (WFD) suggests that there are approximately 72 million deaf signers worldwide (Allen, 2013). The Insign

\footnotetext{
${ }^{1} \mathrm{http}: / /$ bslsignbank.ucl.ac.uk

${ }^{2}$ See http://www.eud.eu

${ }^{3}$ We note, though, that some deaf signers do make extensive use of social media, which
} 
project aimed to improve independent communication and interaction opportunities for deaf citizens with EU institutions, such as the European Parliament or the European Commission (Turner et al., 2016). The specific goal of the Insign project was to develop a concept for a web-based service platform that could be used by any deaf or hard of hearing citizen within the European Union to assist with real-time live sign language interpretation and/or real-time captioning in order to facilitate independent communication with the institutions of the European Union. The project was undertaken in collaboration with the European Union of the Deaf (EUD) ${ }^{2}$, and for the purposes of this paper we focus on deaf signers.

One of the key issues for the Insign project was the need to generate findings that could be easily translated into clear and robust policy recommendations for the European Commission. European Commission initiatives and proposals for legislation must be based on "transparent, comprehensive and balanced evidence on the nature of the problem to be addressed, the added value of EU action and the cost and benefits of alternative courses of action for all stakeholders" (Wilson, 2015, abstract). Young and Temple (2014) challenge the fetishisation of sample sizes within positivist research, reminding us that what counts as a representative sample is relative and highly contested. As they correctly identify, the majority of studies within the field of Deaf Studies research employ qualitative methodologies, for reasons that will be returned to in the next section. However, they argue that 'silo-thinking' within Deaf Studies research has led to a rejection of certain epistemologies and methods, particularly quantitative approaches, to the detriment of research in this area. Like Young and Temple, we want to avoid creating a false dichotomy between the value of qualitative and quantitative research for effecting policy change. Instead, we argue that Deaf Studies researchers should be able to utilise a wide range of methodological approaches in order to meet the needs of the research topic and project.

The Insign project took place over one year (2013-2014); this encompassed all aspects including preliminary research with deaf signers and interpreters, development of the Insign platform, and user testing with Members of the European Parliament (MEPs) and representatives from other European institutions, such as the European Commission. The first phase of the project, described in this paper, aimed to examine the views of deaf signers on their use and experience with Telecommunication Relay Services (textbased or video-based services that enable deaf signers to communicate across telephone networks) (Turner et al., 2016), in order to inform the development of the Insign platform. As a proof-of-concept study, there were significant budget and schedule restrictions, with the majority of time and funds allocated to platform development. These factors, combined with the language abilities of the research team, meant that methods such as surveys, interviews or focus groups with deaf signers across a wide( $\mathrm{r}$ ) range of sign languages were unfeasible. These restrictions presented significant pragmatic challenges for the research team, requiring a creative approach to the research design in order to address the issues of language diversity and methodological scalability identified in the preliminary stages. A review of the literature identified a lack of precedent for effective means of addressing these issues. Table 1 provides an overview of previous studies undertaken on deaf signers' use and experience of Telecommunication Relay Services (TRS).

While these studies may involve more than one language - such as the use of English and ASL in Maiorana-Basas and Pagliaro's (2014) study - no precedent could be found within the existing literature for methodologies that

${ }^{2}$ See http://www.eud.eu 
enabled the recruitment of deaf signers from multiple national contexts (and who therefore might use different signed languages). Therefore, our goal was to optimize the survey for those who either lack literacy in the written language of the survey (i.e. plain English), or those who could technically read and complete the survey in English but prefer to use sign language. Giving deaf signers the option to complete the survey in sign language was an important consideration, because data quality and response rates are likely to be higher in the language in which they are most comfortable. Given that we were targeting deaf signers from multiple European countries, we determined that using International Sign was the only viable option.

Table 1: Overview of previous studies

\begin{tabular}{|c|c|c|c|}
\hline Author & Study & No. of participants & Method(s) \\
\hline $\begin{array}{l}\text { Pilling et al. } \\
(2006)\end{array}$ & $\begin{array}{l}\text { Feasibility of additional } \\
\text { telephone relay } \\
\text { services }\end{array}$ & 17 & $\begin{array}{l}\text { Text-based } \\
\text { questionnaires \& face- } \\
\text { to-face interviews in } \\
\text { American Sign } \\
\text { Language (ASL) }\end{array}$ \\
\hline $\begin{array}{l}\text { National } \\
\text { Consortium of } \\
\text { Interpreter } \\
\text { Education } \\
\text { Centers } \\
\text { (NCIEC, 2008) }\end{array}$ & $\begin{array}{l}\text { Steps towards } \\
\text { identifying effective } \\
\text { practices in video relay } \\
\text { service settings }\end{array}$ & 25 & $\begin{array}{l}\text { Text-based } \\
\text { questionnaires \& face- } \\
\text { to-face interviews in } \\
\text { ASL }\end{array}$ \\
\hline $\begin{array}{l}\text { Lewin et al. } \\
(2009)\end{array}$ & $\begin{array}{l}\text { Voice telephony } \\
\text { services for deaf } \\
\text { signers }\end{array}$ & 21 & 1 focus group in ASL \\
\hline Taylor (2009) & $\begin{array}{l}\text { Video relay services } \\
\text { industry research: New } \\
\text { demands on } \\
\text { interpreters }\end{array}$ & 36 & 5 focus groups in ASL \\
\hline $\begin{array}{l}\text { Connelly (2010, } \\
\text { 2011) }\end{array}$ & $\begin{array}{l}\text { Evaluation of Australian } \\
\text { captioned telephone } \\
\text { trial }\end{array}$ & $161 / 44$ & $\begin{array}{l}\text { Mixture of text-based } \\
\text { surveys \& focus } \\
\text { groups in Australian } \\
\text { Sign Language }\end{array}$ \\
\hline $\begin{array}{l}\text { Russell \& } \\
\text { Demko (2013) }\end{array}$ & $\begin{array}{l}\text { Reducing the social } \\
\text { isolation of rural deaf } \\
\text { Albertan }\end{array}$ & 41 & $\begin{array}{l}\text { Face-to-face } \\
\text { interviews in ASL }\end{array}$ \\
\hline $\begin{array}{l}\text { Shaw \& } \\
\text { Roberson } \\
\text { (2013) }\end{array}$ & $\begin{array}{l}\text { Social connectedness } \\
\text { of deaf retirees }\end{array}$ & 13 & $\begin{array}{l}2 \text { text-based surveys } \\
\& 5 \text { focus groups in } \\
\text { ASL }\end{array}$ \\
\hline $\begin{array}{l}\text { Maiorana-Basas } \\
\& \text { Pagliaro } \\
\text { (2014) }\end{array}$ & $\begin{array}{l}\text { Technology use among } \\
\text { adults who are deaf \& } \\
\text { hard-of-hearing: A } \\
\text { national survey }\end{array}$ & 278 & $\begin{array}{l}\text { Online survey in ASL } \\
\text { \& English }\end{array}$ \\
\hline $\begin{array}{l}\text { Stout, Alkebsi, \& } \\
\text { Vogler (2017) }\end{array}$ & $\begin{array}{l}\text { User survey on various } \\
\text { aspects of video relay } \\
\text { services }\end{array}$ & 468 & $\begin{array}{l}\text { Online survey in } \\
\text { English }\end{array}$ \\
\hline
\end{tabular}

\section{Methodological challenges in undertaking quantitative research with deaf signers}

Research with deaf signers and their respective signing communities has a long tradition of methodological innovation. Existing literature has identified a number of pertinent issues that must be considered in the design of research methodology that aims to include the experiences of deaf participants (e.g., Harris, Holmes, \& Mertens, 2009; Kusters et al., 2017; Napier \& Leeson, 2016; Singleton, Jones, \& Hanumantha, 2012; Singleton et al., 2015; Young \& 
Temple, 2014). These include: the language skills and preferences of the participant; the language skills of the researcher and the mode of communication used; the researcher and participant relationship; and methods of recruitment. These were all issues for the Insign project that were addressed during the research design.

As identified above, spoken or written languages are often second languages for many deaf signers, and literacy levels among them vary significantly (Mayberry, 2010; Strong \& Prinz, 2000). These issues of reading comprehension are clearly highly significant when we consider the ethical and moral importance of the clarity of communication between researcher and participant. Research methods that rely upon communication through spoken and written languages may exclude deaf signers who are not familiar with, or are unable to utilise, languages in these modes. Furthermore, participant confusion regarding the questions being asked in written or spoken form may have a negative impact on the validity of the research results, as the integrity of the research findings in any field is reliant on participants' being able to gain an accurate understanding of what is being asked, and indeed have their own answers understood as precisely as possible. If researchers wish to find out about the experiences and views of people, they should therefore communicate with participants in the language(s) preferred by members of the target population. Furthermore, the Ethics Statement for Sign Language Research (Sign Language Linguistics Society [SLLS], 2016) clearly states that for research with deaf signing communities to be considered ethical, the use of sign language in eliciting data has to be an integral part of the research design. For example, in Russell and Demko's (2013) study, the use of sign language by interviewers provided deaf signers the opportunity to express themselves in ASL through face-to-face interviews, affording deaf participants in hard-toreach locations a rare opportunity to participate in data generation in Deaf Studies projects using their preferred language. Although, ethically, Russell and Demko's study aligned with the Terms of Reference for Sign Language Research in relation to including deaf signers in research and conducting data generation in sign language, this traditional method of using interviews is labour-intensive (Lucas et al., 2013).

While increasing numbers of deaf signers themselves are entering academia (De Meulder, Napier, \& Stone, submitted; Kusters et al., 2017; O'Brien \& Emery, 2013), previous research with deaf signers has often been undertaken by hearing people with varying levels of proficiency in sign languages, with or without the assistance of an interpreter (Harris et al., 2009; Singleton et al., 2012). The translation and interpretation of sign languages into written and spoken languages and vice versa is thus an integral issue in research with deaf signing communities, as it is in conducting research with any language minority communities (Temple, 2002; Temple \& Edwards, 2002; Temple \& Young, 2004). Because of this reliance on interpretation and translation, research with deaf signers has traditionally drawn heavily on faceto-face qualitative methods, such as focus groups and interviews. While such methods are both time- and resource-intensive, particularly in terms of logistical issues, they are highly effective for research with deaf signers (Napier \& Leeson, 2016; Schembri \& Johnston, 2013; Young \& Hunt, 2011). These methods have been shown to generate rich data representing a wide range of opinions (Russell \& Demko, 2013; Schembri \& Johnston, 2013; Young \& Temple, 2014). Their prime advantage is the opportunity for twoway communication between researcher and participants, in sign language, either directly or mediated through an interpreter. This enables research participants to express themselves in their chosen language, while also facilitating clarification of points of misunderstanding in real-time, thus enhancing the validity of the findings. Such verifications become much more difficult in asynchronous methods such as written surveys. 
Deaf Studies researchers experience many similar issues to those encountered by other colleagues in relation to the dynamics of researcherparticipant relationships and barriers to participant recruitment (Baker-Shenk \& Kyle, 1990); for example, whether participants trust the researchers' ethicality and are therefore willing to participate (Corbie-Smith, Thomas, Williams, \& Moody-Ayers, 1999). Both deaf and hearing researchers have to consider perceptions of their 'insider' and 'outsider' status in relation to deaf signing communities (Kusters et al., 2017; Napier \& Leeson, 2016; O’Brien \& Emery, 2013; Sutton-Spence \& West, 2011; Young \& Ackerman, 2001), which may affect recruitment depending on their networks in those communities.

Recruiting deaf signers has been particularly challenging in some respects. ${ }^{3}$ Traditionally, calls for participation have been in text format and relied on the research establishment's connections to deaf signing communities (email or postal invitations, posters, etc.), which may be inaccessible to deaf signers. Researchers are increasingly using dedicated websites that have information presented in sign language (see http://mobiledeaf.org.uk/, for example), since it has been argued that the recruitment of deaf signers and the dissemination of information about projects should be done in a signed language to be considered valid (Adam, 2015). ${ }^{4}$ Nevertheless, there is often still a reliance on 'snowballing' techniques for recruitment, which employ 'word of mouth' to generate interest in research participation among a particular community (or cohort). Snowballing recruitment strategies are often used by researchers working with hard-toreach communities (Atkinson \& Flint, 2001; Napier \& Hale, 2013). The recruitment relies on information about the research being passed on, usually relatively informally, from one person to another. Criticisms of snowballing often centre on the selective nature of the resulting sample and the consequent lack of 'randomness' with recruitment. The concern is that the sample may not be representative of the relevant population, because the recruitment of 'friends of friends' as participants may lead unwittingly to amassing an overly homogenous set of participants. Those who act as go-betweens, or gatekeepers, are likely to inform others like themselves about the opportunity to contribute, or to judge only a subset of the relevant population suitable to be part of the research (Murthy, 2008). The justification for snowballing is often about researching the lives of people outside of the mainstream: sometimes there appears to be no way of knowing who else is part of a target population unless one is an 'insider' oneself. Deaf signing communities in many ways meet this description. Snowballing and purposive sampling are particularly important for recruiting participants from deaf signing communities in relation to issues of trust and accountability: whether participants 'identify' with researchers; whether potential participants really do represent deaf signers; and how participants can then engage in the research process (Hoopes et al., 2001; Kusters et al., 2017; Leeson et al., 2017; Napier et al., 2014; Young \& Temple, 2014). This method has been shown to be effective in reaching harder to reach groups within deaf signing communities (James \& Woll, 2004).

There have been many surveys with deaf signers, but typically these have been in the form of written questionnaires handed out on paper (Middleton, Hewison, \& Mueller, 1998) or administered online (Bowe, 2002). Large-scale surveys investigating the use of communication technologies among deaf signers have been conducted by Power, Power, and Horstmanshof (2007) and Power, Power, and Rehling (2007). The combined results from these two surveys provide insight into the practices of deaf signers who were confident

\footnotetext{
${ }^{3}$ We note, though, that some deaf signers do make extensive use of social media, which provides a basis for rapid recruitment (for those engaged with these media).

${ }^{4}$ See, for example, the BSL Corpus project: http://www.bslcorpusproject.org
} 
about responding to a survey presented in text format; however, these surveys do not capture the views or techno-communication preferences of those deaf individuals who are largely monolingual deaf signers (an issue acknowledged by the surveys' authors).

Questionnaires produced in sign language format began around the 1990s (Lipton, Goldstein, Fahnbulleh, \& Gertz, 1996), and are increasingly used in the field of medical, psychological, mental health, and language assessments (e.g., Boudrealt et al., 2010; Cornes, Rohan, Napier, \& Rey, 2006; Graybill et al., 2010; Rogers et al., 2013). However, producing generic surveys in sign language has still to become general practice, as it has not always been possible to create user-friendly surveys in sign language with ease. Developing a survey in sign language has historically been a challenge because of both cost and complexity in design, production, and distribution. The process once required access to a recording studio and editing suite. Any corrections could not simply be erased and re-written; instead extensive work was needed with re-filming and re-editing the content (Lipton et al., 1996). Therefore, producing surveys in sign language has always had technological disadvantages when compared with the ease of producing text-based surveys.

\section{Impact of new technologies on survey methods in Deaf Studies}

The advent of digital video technologies has presented new opportunities for exploiting technology to conduct quantitative research with deaf signers. Inherently, though, this also creates new challenges. The fact that the opportunities would seem to outweigh the challenges is something that we consider in this paper, with the view that digital video technologies can be harnessed within quantitative methodologies to reach deaf signers in mainstream research.

Mehra, Merkel, and Bishop (2004) note that digital technology can be used as a tool for the empowerment of marginalised groups, while Young and Temple (2014) suggest that "new [digital video] technologies have the potential to create new kinds of knowledge through addressing new forms of knowability and including new populations of knowers" (p.159). Digital video technology has long played a vital role in enabling deaf signers to communicate with one another, and in breaking down barriers that prevent the participation of deaf signers in society (Barak \& Sadovsky, 2008; Bowe, 2002; Power \& Power, 2004; D. Power et al., 2007; Young \& Temple, 2014). The rapid rise in new forms of communication via digital video technology in recent years has created new methodological opportunities for researchers working with deaf signers. The most significant of these for deaf signers are developments in audio-visual technology and the ubiquity of social media.

For deaf signers, digital video technology may be considered the equivalent of the pen and paper (or keyboard and screen) that permit a spoken language to be 're-cast' in text format. There is no other way to capture and transmit signed language in its natural form, except through the use of academic tools and systems designed for a level of detail beyond everyday requirements (Crasborn, 2015). Television programmes are made and presented in sign language, social events are filmed and kept as a historical account, video-based resources replace former 'learn to sign' picture books, and in some cases video messages replace emails or SMS. The demand for more ways to communicate via video has existed in deaf signing communities for some time (Pilling et al., 2006; D. Power et al., 2007; M. Power et al., 2007), and is becoming a reality for many deaf signers (Maiorana-Basas \& Pagliaro, 2014). Deaf signers are benefiting from this ability to make contact via video on their personal devices (Keating \& Mirus, 2003; Keating, Edwards, \& Mirus, 2008; Maiorana-Basas \& Pagliaro, 2014; Russell \& 
Demko, 2013; Shaw \& Roberson, 2013) and the number of deaf social groups online suggests there is a high level of social networking activity across international deaf signing communities, through social media sites such as Facebook, and video messaging apps such as Glide.

There is increasing discussion of the positive technological impact on social contact between deaf signers by virtual means (Young \& Temple, 2014). Social media platforms bring together communities that are not defined by territorial or national boundaries but boundaries defined by shared interests. Now, through technology, international deaf signing communities are able to remain communicatively close via a range of social media platforms. Today, internet speeds in most European nations are robust enough to support video content and video communication; there are easier methods to create personalised video content, and calling via a video link is common (Keating \& Mirus, 2003). In addition to producing high-quality video clips, it has become easier to share the video content. At the turn of the 21st century, when it was not as easy to film, compress, and upload videos online as it is now, researchers had to host designated webpages and find the funds to develop bespoke sites that could host video and text content (Woolfe, Herman, Roy, \& Woll, 2010). In recent years, however, sites such as YouTube and Vimeo where, for example, video upload capacities increased from 20 -second clips in 2007 to 20-minute clips in 2014 (the end year of the project) - have made sharing this content easier. It is now also possible to easily upload videos to Facebook and Twitter.

Working against a plain background, sometimes in front of a blue or green screen, researchers equipped with a standard computer, mobile or tablet can produce high-quality sign language video content. Research projects can now produce stimuli once only possible in text or spoken language format. Until recently, however, it was difficult to embed this content in online survey instruments. In recent years, it has become possible to embed video from YouTube or Vimeo into online survey instruments (Maiorana-Basas \& Pagliaro, 2014; Turner, et al., 2016). This is ideal for presenting questions in a signed language, but due perhaps to a combination of (a) lack of technical skills and software knowledge, and (b) lack of ability to collect open-ended comments through online surveys, it is still rare to see actual survey questionnaires in a signed language. One notable exception is the work of Patrick Boudreault and his colleagues, who developed a battery of four different questionnaires to test deaf adults' motives for genetic testing (Boudrealt et al., 2010; Kobayashi, Boudrealt, Hill, Sinsheimer, \& Palmer, 2013; Palmer, Boudreault, Baldwin, \& Sinsheimer, 2014). The questionnaires were devised in English and translated into Spanish and ASL. In some of their papers, it is not clear in which language respondents could respond, although one publication explicitly states that participants were able to complete the questionnaires in the language of their choice (Palmer et al., 2013). Nevertheless, the questions were still generated in English and translated into ASL, rather than being devised originally in ASL. This process means that questions may have been formulated in a way that makes cross-cultural translation difficult (Mason, 2005). Confidence among researchers in using this approach may therefore remain low.

One challenge of administering an online survey in sign language is how to ensure validity and reliability, because standard translation requirements have to take into account the visual nature of sign language (Rogers et al., 2016). Furthermore, it is difficult to collect individual opinions or thoughts in a signed language if open-ended questions are used. Unfortunately, effective methods for collecting open-ended responses in signed languages are yet to be widely deployed in research. For example, in de Wit and Sluis' (2014) online survey of deaf signers in the Netherlands, questions were presented in Dutch Sign Language, but respondents used written Dutch to give responses. The 
equivalent feature for a signing deaf audience would involve respondents capturing signed responses via their own webcams. Such a feature (online video recording embedded in an online survey) would enable participants to expand or qualify their answers in a signed form. The Scottish Parliament innovatively explored this approach in consulting on the British Sign Language (Scotland) Act 2015, with considerable success. ${ }^{5}$ This type of survey interaction has also been tried with some success in research elsewhere (Lucas et al., 2013) with respondents uploading video responses into the survey tool, to a video site such as YouTube, or to a Dropbox folder. However, while uploading video responses is possible (Lucas et al., 2013), the process is time-consuming, and difficult to manage from a researcher perspective in terms of processing multiple video files and matching these to survey responses. This process requires significant personal investment in the research process on the part of the participant, and also has ethical implications for respondent anonymity (Young \& Temple, 2014). Furthermore, issues of translation costs re-emerge in this process, as signed responses require translation into written languages. Consequently, it is not currently ideal to ask open-ended questions within online sign language surveys. This may limit the usefulness of this method for certain types of research questions.

The use of video content in combination with online survey methods represents a significant opportunity for engaging with populations for whom visual content is the norm. By employing research techniques that resonate with participants' existing modes of engagement, we argue that it is possible to improve communication clarity between researchers and deaf signers as well as engage with a wider range of participants.

\section{What did Insign do?}

Drawing on the outcomes from previous studies (as listed in Table 1), a questionnaire instrument was developed and delivered through the online survey tool Surveyit. It was agreed that the questionnaire instrument should be created in a signed language, and should minimise the amount of written text. It was considered by the project team that the use of International Sign (IS) would be the most efficient way of addressing the issues brought about by the supranational context of the EU in order to avoid the complexities of creating a multilingual signed survey. Developing an online questionnaire in IS meant that the survey could reach participants across several European nations. The survey welcomed deaf signers who had experience of using text-based or sign language-based relay services to respond. Therefore, all fifty questions, which included coverage of demographics and telecommunication trends, and open comment boxes, were signed in IS and also written in plain English with accompanying icons sourced from The Noun Project (thenounproject.com), an online database of 'visual language' (see Figure 1).

The person delivering the questions in IS was a hearing native signer, and an experienced interpreter with a background of working with deaf signers in different countries. The final set of IS questions were shown to an experienced deaf IS user and academic to confirm clarity.

\footnotetext{
5 "We also set up a BSL Facebook group to invite BSL users and others to share their views on the Bill. The initiative was suggested by Professor Graham Turner as providing an easy way for people to communicate their views to us by posting BSL video clips. The initiative was widely welcomed as an excellent example of a public body being inclusive and accessible for Deaf sign language users. Hundreds of BSL videos were shared by the group commenting on the Bill, and the group now has over 2,300 members" (http://www.parliament.scot/parliamentarybusiness/ CurrentCommittees/88810.aspx).
} 


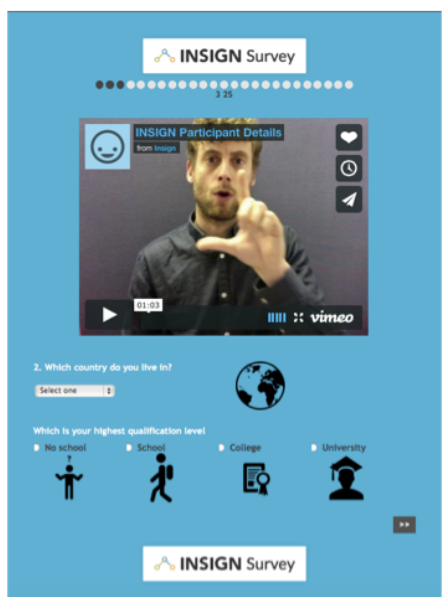

Figure 1: Screen capture of interface of Insign survey instrument

To mitigate the limitation of participants' not being able to respond to the survey in a signed language, we used closed and multiple-choice questions so that respondents simply had to click on their answers by clicking on the visual icon that depicted the signed range of answers that were given. At the end of the survey, respondents were offered the opportunity to provide contact details so that they could be invited to join follow-up interviews in IS via video (for example, through Skype or FaceTime).

The survey was open for two weeks and an invitation to participate was presented in IS with English captions. Responses were explicitly sought from deaf signers only. Using network and snowball sampling techniques (Hale \& Napier, 2013; Young \& Temple, 2014), the invitation was disseminated through the international networks of the Heriot-Watt University research team and the Insign consortium partners (e.g., membership databases of the EUD), through a vlog post, and via various social media networks, such as Twitter and Facebook. The decision to distribute via social media networks was largely taken because of the international reach, the high density of deaf signers on social media (Bodemann, 2012; Gingiss, 2018), the popularity of these networks, and the ability to present the invitation on video in IS.

It is not possible to estimate the absolute number of individuals who would have been aware of the survey, but the reach and significance of the consortium's networks - particularly those of EUD and efsli (European Forum of Sign Language Interpreters) as multinational bodies - suggest that this approach will have opened the opportunity for participation to an appropriate proportion of deaf signers in Europe. The invitation reached 9,984 individuals/organisations via the Insign Facebook page, for example, and was shared by 55 of these recipients (generating scope for an unknown degree of onward dissemination.) Reminders were disseminated repeatedly across the two-week period.

Since we were unable to allow respondents to give open-ended signed comments in response to the questionnaire, a second phase of the survey included interviewing a selection of respondents who took part in the online survey and had indicated that they would be willing to be contacted for follow-up interviews. Interview candidates were balanced for gender, age group, and communication preference. The purpose of the interviews was to further interrogate the results from the online survey. The semi-structured interviews were designed to elicit further information that could not be obtained via the online survey, and to identify particular experiences that were region-specific. Twelve self-identified users of video remote sign language interpreting services and six users of text-based relay services were invited to participate in follow-up interviews. One repeat invitation was sent to those who did not reply to the original request for participation. Eight people replied 
to the interview invitations: six video remote sign language interpreting users, and two people who declared themselves to be both text-based and video remote sign language users.

Two of the follow-up interviews were conducted in British Sign Language (BSL) and the remaining six were in IS. The decision to use BSL or IS was determined by the interviewee. All interviews were video-recorded with known consent, then transcribed by the interviewer (a qualified BSL/English interpreter), and checked by another research team member (also a qualified BSL/English interpreter and accredited as an IS/English interpreter). The qualitative comments of the interview participants were used in the final project report to support the analysis and interpretation of the questionnaire results. As the focus of this paper is on the methods, not the outcomes, an overview of the results of the survey and interviews can be seen in Turner et al. (2016).

\section{Methodological findings: Strengths and limitations of the survey}

In total, 84 deaf signers from 22 different countries completed the full complement of 50 questions in the survey. Seventy-four of these respondents were from 14 different EU countries, and the other 10 respondents were from Australia, North America, and the rest of Europe. From the personal information given, we know that the online survey respondents were predominantly female, middle-aged, educated and employed, with high selfreported sign language proficiency and levels of comfort with technology (as indicated by the number of relevant devices they own). So, although the survey cannot be said to comprise a representative sample of deaf citizens from EU countries (there being no accurate demographic information available on the European deaf population), it nonetheless compiles responses across 14 EU nationalities from 74 individuals who collectively do not share a common signed language. .

So, what certainly seemed to work well was that deaf signers from different countries were able to understand the questions in IS and respond to the questionnaire, even though the questions were not asked in their national signed language. This suggests, in general, that IS can be used to reach deaf signers for cross-border studies, and that digital video technology can be effectively leveraged to enable questionnaires to be administered to different deaf signing communities within the same study. Clear advantages are apparent in the economic and intellectual efficiency of the endeavour. For example, producing questions in the five most common sign languages would have been five times as expensive (plainly significant to funders and research commissioning agents), and have presented greater potential for mistranslation or other presentation inconsistencies which might lead to materially different questions being posed to different sectors of the set of respondents (which could also be an issue for translations in other spoken/written languages).

A number of limitations are nevertheless also identifiable. Given that there are an estimated 750,000 deaf signers in the EU (de Wit, 2016; European Union of the Deaf [EUD], 2001), it is recognised that the sample size of this survey is extremely small for a multi-country study. Nevertheless, as a survey intended to scope issues for further exploration through the Insign project, this offers the first cross-country picture of deaf signers' perceptions of telecommunication services (as opposed to country-specific studies as listed in Table 1), and was felt to be an adequate number for the purposes of this research. This process has provided insight into whether a platform of this nature at a European level would be worthwhile, and also shown that producing a questionnaire in IS does elicit sufficient responses. Relative to 
comparable published work on deaf signers and telecommunication services, the sample is among the largest seen to date.

The respondents were self-selected and it is possible that people who are more likely to use text-based or video remote interpreting services would also make the effort to reply to the survey and participate in interviews; this may affect the outcome. From the survey results, it can be seen that almost $80 \%$ of respondents were college- or university-educated, meaning that they were more likely to be bilingual in a signed and a spoken and/or written language. Unfortunately, it is difficult to know how many of the participants simply would not have participated at all (for reasons of principle or practicality) had the questionnaire not been signed; and we also do not know how many had a higher education, but accessed it predominantly through a signed language (which is now increasingly possible with the provision of interpreters). Similarly, the comments from several interviewees indicate that they work in professional roles, and the number of such participants in the survey seems disproportionate. Therefore, the results should be interpreted carefully, as it would appear that the respondents are more likely to represent 'middle class' deaf signers - an emerging deaf middle class (Padden \& Humphries, 2005), who are well educated, are more likely to value research, and therefore engage with it. However, it could be argued that callers to European institutions from any linguistic community could be expected to be predominantly educated professionals, and so this sample may be entirely appropriate in this context.

Furthermore, we are not able to determine what strategies were used by respondents to complete the survey. It is possible that respondents completed the survey without needing to view the videos. It is also possible the video was only used as an aid because it takes longer to watch videos than to skim read text. This is potentially another area of study describing the strategies used by deaf signers when completing online surveys. In hindsight, it would have been interesting to do usability testing of our instrument to observe respondents engaging with it, or to have collected paradata on the videos, or asked a debriefing question of respondents about their usage of the videos as we do not know to what extent the respondents were only reading the questions and not watching the videos.

We attempted to resolve the limitation of participants not being able to give signed open comments by undertaking follow-up interviews. The semistructured interviews focused on the individual's ontological experience in using telecommunications technology, with a specific focus on relay services. The intention of the interviews was to learn more about positive or negative experiences in using the technology. However, we recognise that the lack of an open comment option in the survey itself may have limited the responses received. Furthermore, although we minimised the use of English in the survey questions, it was still present, and that in itself may have affected potential respondents (for the vast majority of whom, English was neither a first nor second language). We recognise that the ideal would have been to make the survey available in several signed and written languages, but as we mentioned earlier, this would have required a significantly increased budget; and as we also acknowledged earlier, cross-cultural, multilingual survey research is not unproblematic.

The provision of the Insign survey only in IS did not appear to be a major barrier to participation - for us at least the numbers of respondents were sufficient given our research purpose. However, as a research tool, IS is not without its shortcomings. Research has demonstrated that comprehension of IS is not guaranteed, depending on which national signed languages are borrowed from, and which signed language(s) the audience use (Whynot, 2017). Research into the use of IS by deaf presenters and interpreters undertaken by Rosenstock $(2004,2008,2016)$ highlighted that although it is easier to comprehend than other unfamiliar sign languages, significant loss of 
information is common in IS. It has been reported that IS interpreters have a slower and more deliberate use of sign language production through increased use of visual metaphors (McKee \& Napier, 2002), and making greater use of visual depicting signs (Stone \& Russell, 2016), than do national sign language interpreters. Arguably, this kind of language use creates a more formal tone to such communication, an issue that is amplified by the fact that IS has historically been limited to international gatherings, particularly within the political sphere, rather than as a feature of everyday communication (Turner \& Napier, 2014). For those research respondents who are not already active in such settings, the degree to which they feel comfortable with using IS may have influenced their participation. It is also worth considering that the respondents may actually have understood the written English version of the question better than the IS version, even with written English probably being a third language for them.

These issues are amplified by the fact that users of IS may be perceived as an 'elite group' by deaf signing communities (Moody, 2002). The research team's (non-systematic) observation in the field is that individuals who use IS may be perceived as holding high levels of social capital and power (reflecting the formal milieus in which IS sometimes appears). This may present a barrier to research participant recruitment as potential respondents may feel that a survey conducted in IS may not be relevant to them. Despite these drawbacks, the potential of IS as a transnational tool for communication remains valuable to both researchers and participants, as evidenced by the number of responses that were received.

Researchers seek to design and disseminate a survey that is likely to retrieve the greatest response from a specific community. To achieve this ideal, consideration must be given to the clarity and suitability of the language used for the survey. Respondents can only confidently participate in a survey if they are using a spoken or signed language with which they are familiar. In countries where multiple national spoken languages are used, multiple versions of a survey can and do exist: For example, researchers working in Switzerland or Belgium may routinely adopt such an approach and produce surveys in Italian, French, and German; or French and Dutch, respectively, to ensure participation of all citizens in those countries. To maximise participation from deaf signers, the same logic should be considered for the different sign language communities present within one nation - for example, Switzerland, where forms of Italian, French, and German Sign Languages are used. For studies aiming to attract a more global, multi-country audience, we have demonstrated that the use of International Sign can be a consideration.

One of the drawbacks of creating the reported survey instrument in sign language is that its compilation - uploading videos to Vimeo, editing the content, and conducting internal checks - took a significant amount of time. For some potential participants, related technical problems may have led to incomplete survey responses $(n=16)$. Furthermore, signed surveys demand a lengthy time-commitment from respondents, so participant engagement may be limited. Thus, researchers need to be careful about any assumptions regarding the use of digital technology to enable research with deaf signers. Digital technologies that can be used by deaf signers are in many ways still in their infancy, but will develop rapidly: future researchers may be able to develop more sophisticated ways of surveying deaf signers.

Having the qualitative follow-up interviews gave us the opportunity to delve deeper into the questions and have our respondents give their answers in a signed language, so for that reason we would recommend this approach in conjunction with a quantitative IS survey. Until open-ended answers can be built into surveys in such a way as to effectively capture deaf respondents' signed responses, it could still be considered best practice to do this type of qualitative follow-up. However, as technologies progress it may be easier to 
develop and administer surveys where deaf people can watch and respond to questionnaires in multiple sign languages, including with open-ended questions.

\section{Conclusions}

We suggest that these developments, and our learning from the Insign project, offer scope for a broader range of research methodologies that can be used to examine the needs and experiences of deaf signers in contemporary societies. Deploying and further developing these approaches, researchers outside of Deaf Studies could conduct research on any topic with deaf signers as part of their target population ${ }^{6}$. There are acknowledged challenges to including deaf signers in mainstream studies, but this research illustrates that they can be tackled even as others still remain.

We have suggested that, in addition to enhancing research within the field of Deaf Studies, these methodological tools could be utilised by researchers within 'mainstream' academic research to examine topics that go beyond solely 'deaf or sign language issues' towards broader issues. The need for these alternative methodologies is a question not just of ethics but of academic rigour: Given that there are estimated to be 72 million deaf signers across the world (Allen, 2013), it is right that their views and experiences should be more widely represented within the data populations of academic research. As Young and Temple (2014) argue, conducting research with deaf signers and signing communities "contributes to, challenges and changes wider (non-deafrelated) debates and practice in these areas" (p. 5).

Given the preceding discussion, our basic recommendations when developing a survey questionnaire instrument in a signed language are therefore to:

- Determine the target audience and the likely sign languages to be present within that community.

- Maximise lucidity by recording signed questions through an experienced and linguistically skilled signer, which will typically mean someone who is deaf or a hearing native signer.

- Seek feedback and input, insofar as practicable, on the completed signed questions before launching the survey, from persons whose background is comparable to that of the target audience.

- Consider including a question on language proficiency in a written language as well as a signed language, in order to understand whether respondents required a sign language version of the instrument or preferred it.

- Collect paradata from survey instruments to determine the extent to which respondents actually watched the videos or read the written questions.

Online sign language surveys could become the standard approach for researchers surveying deaf signing communities, replacing the once dominant text-based format. Overall, this means the language choice used to conduct the entire research process can begin at concept and development with a signed language. However, there is some way to go before we can declare that we have overcome the challenges of creating questionnaire instruments in sign language. We have shown, however, that video technology can be usefully employed if a quantitative approach is required, especially if time and

\footnotetext{
${ }^{6}$ We note that any research specifically on deaf populations and their sign language use should be done in conjunction with researchers who are themselves deaf signers.
} 
geographical spread are important, and that it is possible to effectively design and administer questionnaires to deaf signers in signed language.

\section{References}

Adam, R. (2012). Language contact and borrowing. In R. Pfau, M. Steinbach, \& B. Woll (Eds.), Sign language: An international handbook (pp. 841-861). Berlin: De Gruyter Mouton.

Adam, R. (2015) Dissemination and transfer of knowledge to the Deaf community. In E. Orfanidou, B. Woll, \& G. Morgan (Eds.), Research methods in sign language studies: A practical guide (pp. 41-52). London: Wiley Blackwell.

Allen, C. (2013). Equality for Deaf sign language users: How do we get there? In Centre for Deaf Studies Occasional Lecture Series. Trinity Long Room Hub, Trinity College Dublin.

Allsop, L., Woll, B., \& Brauti, J. M. (1995). International Sign: The creation of an international Deaf community and sign language. In H. F. Bos \& G. M. Schermer (Eds.), Sign language research 1994: Proceedings of the $4^{\text {th }}$ European Congress on Sign Language Research (pp. 171-188). Hamburg: Signum Press.

Atkinson, R., \& Flint, J. (2001). Accessing hidden and hard-to-reach populations: Snowball research strategies. Social Research Update, 33. Retrieved from http:// citeseerx.ist.psu.edu/viewdoc/download?doi=10.1.1.304.5163\&rep=rep1\&type= pdf

Baker-Shenk, C., \& Kyle, J. (1990). Research with Deaf sign language users: Issues and conflicts. Disability, Handicap \& Society, 5(1), 65-75.

Barak, A., \& Sadovsky, Y. (2008). Internet use and personal empowerment of hearing-impaired adolescents. Computers in Human Behaviour, 24, 1802-1815.

Bat-Chava, Y. (2000). Diversity of deaf identities. American Annals of the Deaf, 145(5), 420-27.

Batterbury, S., Ladd, P., \& Gulliver, M. (2007). Sign language peoples as indigenous minorities: Implications for research and policy. Environment \& Planning, 39(12), 2899-2915.

Bodemann, M. (2012). Building interaction with an isolated population through social media: The Deaf community. Unpublished Undergraduate Honours Dissertation, University of Arkansas. Retrieved from http://scholarworks.uark. edu/rhrcuht/13

Boudreault, P., Baldwin, E., Fox, M., Dutton, L., Tullis, L., Linden, J., ... Palmer, C. (2010). Deaf adults' reasons for genetic testing depend on cultural affiliation: Results from a prospective, longitudinal genetic counseling and testing study. Journal of Deaf Studies \& Deaf Education, 15(3), 209-227.

Bowe, F. (2002). Deaf and hard-of-hearing Americans' instant messaging and e-mail use: A national survey. American Annals of the Deaf, 147(4), 6-10.

Breivik, J. (2005). Deaf identities in the making: Local lives, transnational connections. Washington, DC: Gallaudet University Press.

Cannon, J., \& Guardino, C. (2013). Literacy strategies for Deaf/Hard-of-Hearing English language learners: Where do we begin? Deafness \& Education International, 14(2), 78-99.

Corbie-Smith, G., Thomas, S. B., Williams, M. V., \& Moody-Ayers, S. (1999). Attitudes and beliefs of African Americans toward participation in medical research. Journal of General Internal Medicine, 14(9), 537-546.

Cornes, A., Rohan, M., Napier, J., \& Rey, J. (2006). Reading the signs: Impact of signed vs. written questionnaires on the prevalence of psychopathology among deaf adolescents. Australia \& New Zealand Journal of Psychiatry, 40(8), 665673.

Crasborn, O. A. (2015). Transcription and notation methods. In E. Orfanidou, B. Woll, \& G. Morgan (Eds.), Research methods in sign language studies: A practical guide (pp. 74-88). London: Wiley Blackwell.

De Meulder, M., Napier, J., \& Stone, C. (submitted). It takes three to tango? A case study of a deaf academic and two signed language interpreters working together for a $\mathrm{PhD}$ defense.

de Wit, M. (2016). Sign language interpreting in Europe ( $2^{\text {nd }}$ Ed.). Netherlands: Create Space, Self-publishing. 
de Wit, M., \& Sluis, I. (2014). Sign language interpreter quality: The perspective of deaf sign language users in the Netherlands. The Interpreters' Newsletter, 19, 63-68.

European Union of the Deaf. (2001). EUD update. Special Edition: Update on the status of sign languages in the European Union. Brussels: European Union of the Deaf.

Forsyth, B.H., Kudela, M. S., Levin, K., Lawrence, D., \& Willis, G. B. (2007). Methods for translating an English-language survey questionnaire on tobacco use into Mandarin, Cantonese, Korean, and Vietnamese. Field Methods, 19, 264 283.

Freel, B. L., Clark, M. D., Anderson, M. L., Gilbert, G. L., Musyoka, M. M., \& Hauser, P. C. (2011). Deaf individuals' bilingual abilities: American Sign Language proficiency, reading skills, and family characteristics. Psychology, 2(1), 18-23.

Gingiss, D. (2018). How social media became a game changer for the Deaf community. Retrieved from https:/www.socialmediatoday.com/news/how-social -media-became-a-game-changer-for-the-deaf-community/514223

Graybill, P., Aggas, J., Dean, R., Demers, S., Finigan, E., \& Pollard, R. Q. (2010). A community participatory approach to adapting survey items for deaf individuals and American Sign Language. Field Methods, 22(4), 429-448.

Gregg, A., Atherton, M., Quinn, G., Traynor, N., Turner, G. H., \& Laugesen, C. (2002). Addressing communication disadvantage: Deaf sign language users with minimal language skills. Unpublished research report: Deafway/Community Fund.

Hale, S., \& Napier, J. (2013). Research methods in interpreting: A practical resource. London: Bloomsbury.

Hansen, M. (2016). What is International Sign? The linguistic status of a visual transborder communication mode. In R. Rosenstock \& J. Napier (Eds.), International Sign: Linguistic, usage and status issues (pp. 15-34). Washington, DC: Gallaudet University Press.

Harkness, J., Braun, M., Edwards, B., Johnson, T., Lyberg, L., Mohler, P., \& Smith, T. (Eds.), (2010). Survey methods in multinational, multiregional and multicultural contexts. London: Wiley Blackwell.

Harris, R., Holmes, H., \& Mertens, D. (2009). Research ethics in signing communities. Sign Language Studies, 9(2), 104-131.

Hiddinga, A., \& Crasborn, O. (2011). Sign languages and globalization. Language and Society, 40(4), 483-505.

Hoopes, R., Rose, M., Bayley, R., Lucas, C., Wulf, A., Petronio, K., \& Collins, S. (2001). Analysing variation in sign languages: Theoretical and methodological issues. In V. Dively, M. Metzger, S. Taub, \& A. M. Baer (Eds.), Signed languages: Discoveries from international research (pp.135-162). Washington, DC: Gallaudet University Press.

James, M., \& Woll, B. (2004). Black Deaf or Deaf Black? Being Black and Deaf in Britain. In A. Pavelenko \& A. Blackledge (Eds.), Negotiation of identities in multilingual contexts (pp. 125-160). Clevedon: Multilingual Matters.

Jokinen, M. (2001). The Sign Language Person - a term to describe us and our future more clearly? In L. Leeson (Ed.), Looking forward: EUD in the 3rd millennium the deaf citizen in the 21st century (pp. 50-63). Coleford: Douglas Maclean.

Keating, E., \& Mirus, G. (2003). American Sign Language in virtual space: Interactions between Deaf users of computer-mediated video communication and the impact of technology on language practices. Language in Society, 32, 693714 .

Keating, E., Edwards, T., \& Mirus, G. (2008). Cybersign and new proximities: Impacts of new communication technologies on space and language. Journal of Pragmatics, 40(6), 1067-1081.

Kobayashi, Y., Boudrealt, P., Hill, K. Sinsheimer, J., \& Plamer, C. (2013). Using a social marketing framework to evaluate recruitment of a prospective study of genetic counselling and testing for the deaf community. BMC Medical Research Methodology, 13.

Kusters, A. (2010). Deaf utopias? Reviewing the sociocultural literature on the world's 'Martha's Vineyard situations'. Journal of Deaf Studies \& Deaf Education, 15(1). 3-16.

Kusters, A., \& Friedner, M. (2015). DEAF-SAME and difference in international deaf 
spaces and encounters. In M. Friedner \& A. Kusters (Eds.), It's a small world: International deaf spaces and encounters (pp. ix-2). Washington, DC: Gallaudet University Press.

Kusters, A., De Meulder, M., \& O'Brien, D. (2017). Innovations in Deaf Studies: Critically mapping the field. In A. Kusters, M. De Meulder, \& D. O’Brien (Eds.), Innovations in Deaf Studies: The role of deaf scholars (pp. 1-56). Oxford: Oxford University Press.

Ladd, P. (2003). Understanding deaf culture: In search of Deafhood. Clevedon: Multilingual Matters.

Leeson, L., Napier, J., Skinner, R., Lynch, T., Venturi, L., \& Sheikh, H. (2017). Conducting research with deaf sign language users. In J. McKinley \& H. Rose (Eds.), Doing research in applied linguistics: Realities, dilemmas, and solutions (pp. 134-145). London: Routledge.

Leigh, I. (2009). A lens on deaf identities. New York, NY: Oxford University Press.Lipton,

Lipton, D. S., Goldstein, M. F., Fahnbulleh, F. W., \& Gertz, E. N.(1996). The interactive video-questionnaire: A new technology for interviewing deaf persons. American Annals of the Deaf, 141(5), 370-378.

Lucas, C. (2001). Sociolinguistics of sign languages. New York: Cambridge University Press.

Lucas, C., Mirus, G., Palmer, J., Roessler, N., \& Frost, A. (2013). The effect of new technologies on sign language research. Sign Language Studies, 13(4), 541-64.

Maiorana-Basas, M., \& Pagliaro, C. M. (2014). Technology use among adults who are deaf and hard of hearing: A national survey. Journal of Deaf Studies and Deaf Education, 19(3), 400-410.

Mason, T. C. (2005). Cross-cultural instrument translation: Assessment, translation, and statistical applications. American Annals of the Deaf, 150(1), 67-72.

Mayberry, R. (2010). Early language acquisition and adult language ability: What sign language reveals about the critical period for language. In M. Marschark \& P. Spencer (Eds.), The Oxford handbook of Deaf Studies, language \& education, Volume 2 (pp. 281-291). New York: Oxford University Press.

McKee, R. \& Napier, J. (2002). Interpreting into International Sign Pidgin: An analysis. Journal of Sign Language and Linguistics, 5(1), 27-54.

Mehra, B., Merkel, C., \& Bishop, A. P. (2004). The internet for empowerment of minority and marginalized users. New Media Society, 6(6), 781-802.

Middleton, A., Hewison, J., \& Mueller, R. F. (1998). Attitudes of Deaf adults toward genetic testing for hereditary deafness. American Journal of Human Genetics, 63(4), 1175-1180.

Monaghan, L., Schmaling, C., Nakamura, K., \& Turner, G. H. (Eds.) (2003). Many ways to be Deaf: International variation in Deaf communities. Washington, DC: Gallaudet University Press.

Moody, W. (2002). International Sign: A practitioner's perspective. Journal of Interpretation, 12, 1-47.

Murthy, D. (2008). Digital ethnography: An examination of the use of new technologies for social research. Sociology, 42(5), 837-855.

Napier, J., \& Leeson, L. (2016). Sign language in action. London: Palgrave.

Napier, J., Sabolcec, J., Hodgetts, J., Linder, S., Mundy, G., Turcinov, M., \& Warby, L. (2014). Direct, translated or interpreter-mediated? A qualitative study of access to preventative and on-going healthcare information for Australian Deaf people. In B. Nicodemus \& M. Metzger (Eds.), Investigations in healthcare interpreting (pp. 51-89). Washington, DC: Gallaudet University Press.

Napier, J., Skinner, R., \& Turner, G. H. (2017). "It's good for them but not so for me": Inside the sign language interpreting call centre. International Journal of Translation \& Interpreting Research, 9(2), 1-23.

NCIEC. (2008). Steps toward identifying effective practices in VRS interpreting. Retrieved from http://www.nciec.org/projects/docs/Steps_VRS_2008Report.pdf.

O’Brien, D. (2017). Deaf-led Deaf Studies: Using Kaupapa Māori principles to guide the development of Deaf research practices. In A. Kusters, M. De Meulder, \& D. O'Brien (Eds.), Innovations in Deaf Studies: The role of deaf scholars (pp. 5776). Oxford: Oxford University Press.

O'Brien, D., \& Emery, S. (2013). The role of the intellectual in minority group studies: Reflections on Deaf Studies in social and political contexts. Qualitative Inquiry, 20(1), 27-36. 
Padden, C., \& Humphries, T. (2005). Inside Deaf culture. Cambridge, MA: Harvard University Press.

Palmer, C., Boudreault, P., Baldwin, E., \& Sinsheimer, J. (2014). Impact of genetic counseling and Connexin-26 and Connexin-30 testing on Deaf identity and comprehension of genetic test results in a sample of Deaf adults: A prospective, longitudinal study. PLOS One, 9(11). Retrieved from https://doi.org/10.1371/jour nal.pone.0111512

Palmer, C., Boudreault, P., Baldwin, E., Fox, M., Deignan, J., Kobayashi, Y., ... Sinsheimer, J. (2013). Deaf genetic testing and psychological well-being in Deaf adults. Journal of Genetic Counseling, 22, 492-507.

Pilling, D., Fleming, S., Pechey, B., Barrett, P., \& Floyd, M. (2006). OFCOM: Feasibility of Additional Telephone Relay Services. Final Report. London: City University. Retrieved from https://stakeholders.ofcom.org.uk/binaries/research/t elecomsresearch/\%20relayreport.pdf

Power, D. J., Power, M. R., \& Rehling, B. (2007). German deaf people using text communication: Short message service, TTY, relay services, fax, and e-mail. American Annals of the Deaf, 152(3), 291-301.

Power, M. R., Power, D., \& Horstmanshof, L. (2007). Deaf people communicating via SMS, TTY, relay service, fax, and computers in Australia. Journal of Deaf Studies and Deaf Education, 12(1), 80-92.

Rogers, K., Pilling, M., Davies, L., Belk, R., Nassimi-Green, C., \& Young, A., (2016). Translation, validity and reliability of the British Sign Language (BSL) version of the EQ-5D-5L. Quality of Life Research, 25(7), 1825-1834.

Rogers, K., Young, A., Lovell, K., Campbell, M., Scott, P., \& Kendal, S. (2013). The British Sign Language versions of the patient health questionnaire, the generalized anxiety disorder 7-item scale, and the work and social adjustment scale. Journal of Deaf Studies and Deaf Education, 18(1), 110-122.Rosenstock, R. (2004). An investigation of international sign: Analyzing structure and comprehension (Unpublished doctoral dissertation). Washington, D.C.: Gallaudet University.

Rosenstock, R. (2008). The role of iconicity in international sign. Sign Language Studies, 8(2), 131-159.

Rosenstock, R. (2016). Comprehension of expository International Sign. In R. Rosenstock \& J. Napier (Eds.), International sign: Linguistic, usage, and status issues (pp. 84-104). Washington, DC: Gallaudet University Press.

Rosenstock, R., \& Napier, J. (2016). To International Sign or not to International Sign? That is the question. In R. Rosenstock \& J. Napier (Eds.), International sign: Linguistic, usage, and status issues (pp. 1-14). Washington, DC: Gallaudet University Press.

Russell, D., \& Demko, R. (2013). Reducing the social isolation of rural Deaf Albertans. Retrieved from http://www.ardn.ca/documents/ARDN-016\%20-Final $\% 20$ Report $\% 20$ to\%20HS.pdf

Schembri, A., \& Johnston, T. (2013). Sociolinguistic aspects of variation and change. In R. Pfau, M. Steinbach, \& B. Woll (Eds.). Sign language: An international handbook (pp.788-816). Berlin: De Gruyter Mouton.

Schembri, A., \& Lucas, C. (2015). Sociolinguistics and deaf communities. Cambridge: Cambridge University Press.

Sha, M., \& Pan, Y. (2013). Adapting and improving methods to manage cognitive pretesting of multilingual survey instruments. Survey Practice, 6(4). Retrieved from http://www.surveypractice.org/index.php/SurveyPractice/article/view/253/p df

Shaw, S., \& Roberson, L. (2013). Social connectedness of Deaf retirees. Educational Gerontology, 39(10), 750-760.

Singleton, J., Jones, G., \& Hanumantha, S. (2012). Deaf friendly research? Toward ethical practice in research involving deaf participants. Deaf Studies Digital Journal, 3. Retrieved from http://dsdj.gallaudet.edu/index.php?issue=4\&section_ $\mathrm{id}=2 \&$ entry_id $=123$

Singleton, J., Martin, A., \& Morgan, G. (2015). Ethics, deaf-friendly Research, and good practice when studying sign languages. In E. Orfanidou, B. Woll, \& G. Morgan (Eds.), Research methods in sign language studies: A practical guide (pp. 7-20). London: Wiley Blackwell.

SLLS (2016). SLLS ethics statement for sign language research. Retrieved from http://slls.eu/slls-ethics-statement 
Stamp, R., Schembri, A., Fenlon, J., Rentelis, R., Woll, B., \& Cormier, K. (2014). Lexical variation and change in British Sign Language. PLoS ONE, 9(4), e94053.

Stone, C., \& Russell, D. (2016). Comparative analysis of depicting signs in International Sign and natural sign language interpreting. In R. Rosenstock \& J. Napier (Eds.), International sign: Linguistic, usage, and status issues (pp. 6582). Gallaudet University Press.

Strong, M., \& Prinz, P. (2000). Is American Sign Language skill related to English literacy? In C. Chamberlain, J. Morford, \& R. Mayberry (Eds.), Language acquisition by eye (pp. 131-142). New York: Psychology Press.

Supalla, T. (1991). Grammatical structure of international signs. Equality \& SelfReliance: Proceedings of the XI World Congress of the World Federation of the Deaf (pp. 762-763).

Supalla, T., \& Webb, R. (1995). Grammatical structure of international sign: A new look at pidgin languages. In K. Emmorey \& J. S. Reilly (Eds.), Language, gesture and space (pp. 333-352). Hillsdale, NJ: Erlbaum.

Sutton-Spence, R., \& West, D. (2011). Negotiating the legacy of hearingness. Qualitative Inquiry, 17(5), 422-432.

Taylor, M. (2009). Video Relay Services Industry Research: New demands on interpreters. Unpublished research report.

Temple, B. (2002). Crossed wires: Interpreters, translators, and bilingual workers in cross language research. Qualitative Health Research, 12(6), 844-854.

Temple, B., \& Edwards, R. (2002). Interpreters/translators and cross-language research: Reflexivity and border crossings. International Journal of Qualitative Methods, 1(2), 1-12.

Temple, B., \& Young, A. (2004). Qualitative research and translation dilemmas. Qualitative Research, 4(2), 161-178.

Turner, G. H. (1994). How is Deaf Culture? Another perspective on a fundamental concept. Sign Language Studies, 83, 103-123.

Turner, G. H. (2007). “I'll tell you later": On institutional audism. Deaf Worlds, 22(3), 50-70.

Turner, G. H., \& Napier, J. (2014). On the importance of professional sign language interpreting to political participation. In A. Pabsch (Ed.), UNCRPD Series: Political participation (pp. 54-71). Brussels: European Union of the Deaf.

Turner, G. H., Napier, J., Skinner, R., \& Wheatley, M. (2016). Telecommunication relay services as a tool for deaf political participation and citizenship. Information, Communication \& Society, 20(10), 1521-1538.

Walker, J. (2016). The deaf researcher: Developing communities of practice: Methods and methodologies. Paper presented at the Bridging the Gap 4 Conference, University of Brighton, $12^{\text {th }}$ November 2016.

Whynot, L. (2017). Understanding International Sign: A sociolinguistic study. Washington, DC: Gallaudet University Press.

Wilson, J. (2015). Evidence-based policy making in the European Commission. Retrieved from https://ec.europa.eu/jrc/en/publication/evidence-based-policy-ma king-european-commission

Woolfe, T., Herman, R., Roy, P., \& Woll, B. (2010). Early vocabulary development in deaf native signers: A British Sign Language adaptation of the communicative development inventories. Journal of Child Psychology \& Psychiatry, 51(3). 322331.

Young, A., \& Ackerman, J. (2001). Reflections on validity and epistemology in a study of working relations between Deaf and hearing professionals. Qualitative Health Research, 11(2), 179-189.

Young, A., \& Hunt, R. (2011). Research with D/deaf sign language users. (Unpublished research report). UK: NIHR School for Social Care Research.

Young, A., \& Temple, B. (2014). Approaches to social research: the case of Deaf Studies. New York: Oxford University Press.

Zeshan, U. (2015). "Making meaning": Communication between sign language users without a shared language. Cognitive Linguistics, 26(2), 211-260. 